Wael T Al Wattar

BDS, MSc (Lec.)

Wafaa K Fathi

BDS, MSc (Lec.)

\section{A clinical comparative evaluation between upper and lower first molar apicectomy procedures (A retrospective trial).}

\section{Department Oral and Maxillofacial surgery} College of Dentistry, University of Mosul

Department Oral and Maxillofacial surgery College of Dentistry, University of Mosul

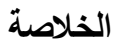

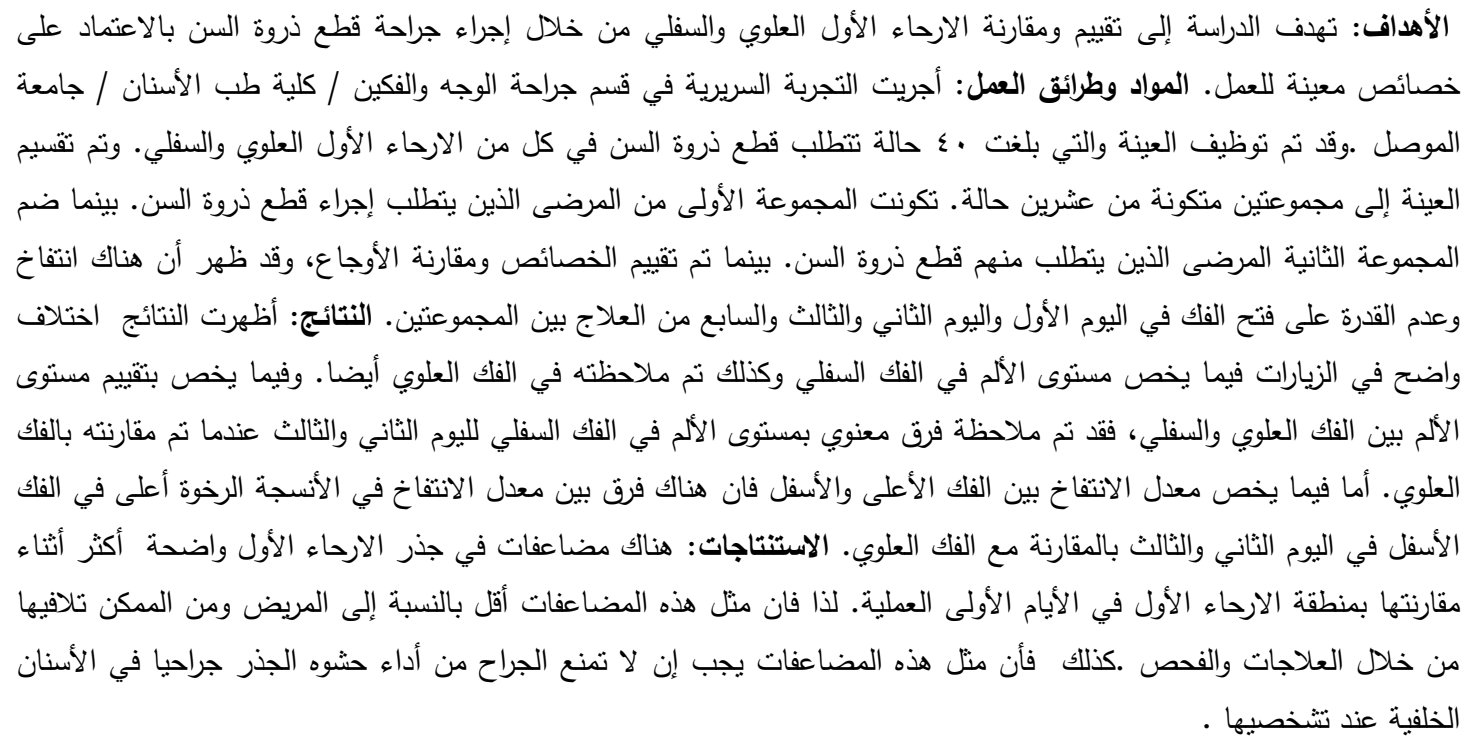

\title{
ABSTRACT
}

Aims: The aim of this retrospective clinical trial was to evaluate and compare the upper and lower first molar apicectomy procedures in terms based on certain clinical criteria selected. Materials and Methods: This clinical trial was conducted at the Department of Oral and Maxillofacial Surgery / College of Dentistry / University of Mosul. The sample recruited was composed of forty healthy subjects who required apicectomy procedures on either an upper or lower fist molar. The sample was subdivided into two groups of twenty subjects each. The first group comprised those patients where root end resection ( apicectomy ) on an upper first molar tooth was required. The second group included those patients who required an apicectomy procedure on one of their lower first molar tooth . Criteria that were evaluated and compared included pain, swelling and trismus which were evaluated on the first operative day, second, third and seventh postoperative day. Results: A significant difference was observed between recall visits in regard to the pain level of mandibular procedures and was also observed in maxillary procedures. In regard to pain level assessment between mandibular and maxillary procedures, a significant difference was observed with pain levels higher in mandibular procedures for the second and third day when compared to maxillary procedures. A significant difference was observed between recall visits in regard to swelling of soft tissue of mandibular and maxillary procedures. Concerning grade of swelling assessment between mandibular and maxillary procedures, a significant difference was observed with swelling of soft tissue higher in mandibular procedures on the second and third day when compared to maxillary procedures. A significant difference was observed for limitation of mouth opening in mandibular procedures between recall visits specifically on the first and second day but was not observed in maxillary procedures. When comparing between upper and lower surgical procedures, a significant difference was observed in trismus specially on the second and third post-operative day and which was more pronounced in mandibular procedures. Conclusions: It seems that complications following root end resection on lower first molar teeth are more evident when compared to the upper first molar region, but only in the first few days following surgery. However, such complications were tolerable to the patient and can be overcome by medications and exercise. Such complications should not hinder the oral surgeon from performing endodontic surgery on posterior teeth when indicated. 
Key words: Molar apicectomy procedures, periapical surgery root end resection, surgical endodontics.

Al Wattar WT, Fathi WK. A clinical comparative evaluation between upper and lower first molar apicectomy procedures (A retrospective trial). Al-Rafidain Dent J. 2011; 11(2): 381-389.

Received: $14 / 9 / 2010$

Sent to Referees: $14 / 9 / 2010$

Accepted for Publication: 27/9/2010

\section{INTRODUCTION}

Countless teeth have been extracted because an exposed or painful tooth was considered untreatable ${ }^{(1)}$. Practitioners of dentistry have been confronted with this problem since the beginning of dental practice. Modern dentistry recognizes preventive, conservative, and restorative types occupying the time of dentists in practice. ${ }^{(2)}$ Endodontic root canal treatment is one of the conservative methods used for maintaining vital tooth, moribund tooth or non-vital tooth in function in dental arch. ${ }^{(1)}$ Root canal treatment is a relatively successful procedure if diagnosis and technical aspects are carefully performed. ${ }^{(3)}$ Studies have reported that the success of endodontic therapy, and it varies from $40 \%$ to $90 \%{ }^{(4,5)}$ Whilst a high degree of success is achievable with root canal treatment, surgery may be necessary to remove etiological factors that may impair tooth retention. ${ }^{(6)}$ Contemporary endodontic surgical procedures have become major considerations in the management of tooth roots and associated periradicular disease. The most common surgical endodontic procedures consist of periradicular curettage, root end resection (apicectomy), root end preparation and root end filling(retrograde filling). ${ }^{(7)}$ Many general practitioners and most oral surgeons routinely perform periradicular surgery on the anterior teeth and premolars. However, they should be able to perform such a procedure on any root in the dental arch, including maxillary and mandibular molars. The tooth types which are mainly extracted more than others are lower first molar and upper first molar. ${ }^{(8)}$ In the present study, apicectomy of upper and lower first molars was performed and compared in terms of certain clinical criteria hoping to be used as a routine surgical endodontic procedure as an alternative to tooth extraction.

\section{MATERIALS AND METHODS}

This clinical trial was conducted at the
Department of Oral and Maxillofacial Surgery / College of Dentistry / University of Mosul. The age of patients ranged between 20 to 40 years and of both genders. The sample recruited composed of forty healthy subjects according to the following inclusion criteria:

1. No history of allergy to local anesthesia.

2. Non - smoking patient.

3. No history of having hemorrhagic diathesis or anticoagulants intake or any systemic problem that would imped oral surgery.

4. Female patients who are pregnant, lactating or taking oral contraceptives were excluded.

5. All patients selected were those who required periapical surgery on an upper or lower first molar tooth where either there was an evident failure of previous root canal therapy ( curved root, obstructed canal...ect) and / was associated with a periapical radiolucency of large size that was evident on periapical radiography.

6. Any case in which acute inflammation was evident in the region of surgery was to be rendered chronic ( access opening, pulp extirpation, removal of old root canal filling if present, instrumentation, prescription of necessary medication, home care instructions, ect... ) and one week should elapse before surgery.

A standard surgical protocol was adopted during the procedure on both teeth and as follows:

1. For local anesthesia; infiltration anesthesia using 2 cartridges $(1.8 \mathrm{ml})$ of $2 \%$ Lignocaine HCL with 1:80.000 adrenaline ( New Stetic - Made in Colombia) for maxillary first molar site and inferior alveolar block plus infiltration of long buccal nerve injection using the same amount and concentration for mandibular first molar.

2. Flap design; for upper first molar : using a number 15 Bard Parker scalpel blade ( Made in England), a two sided flap was raised extending from the interproximal region between the upper first and second 
premolar teeth passing posteriorly to involve the gingival sulcus of the upper second molar. For the lower first molar tooth region, a two sided flap was raised extending from the interproximal region between the lower canine and first premolar tooth passing posteriorly to involve the gingival sulcus of the lower second molar. Flap reflection was performed using a Howarths periosteal elevator and was gently maintained retracted from the operation site during surgery on bone. Care taken near the region of the mental foramen.

3 . For bone removal and apical root resection, a medium size round bur mounted on a straight surgical handpiece (18000$25000 \mathrm{rpm})$ attached to an air motor apparatus (W \& H- made in Austria) was used. Constant cooling was maintained using normal physiological solution ( $0.9 \%$ $\mathrm{NaCl}-\mathrm{Made}$ in Egypt) during the procedure. After gaining visual and mechanical access, any clinically evident periapical lesion around the roots was removed using a curette. For the upper first molar tooth, apical third resection of root was carried out for the mesial, distal and palatal roots ( the latter being around $1 \mathrm{~cm}$ distance from the buccal cortical plate ${ }^{7}$ ). For lower first molar teeth, apical root resection of mesial ( mesiobuccal and mesiolingual roots) and distal roots was carried out.

4. At completion of mechanical removal of pathosis and apical thirds of roots for both teeth, the bony cavity was isolated with gauze and root canal filling was carried out for both teeth. Excess root filling material beyond the root was removed with a small head burnisher heated on a spirit lamp.

5. The bony cavity was then irrigated to remove debris and the flap was closed and sutured with simple interrupted suture technique.

6. Both verbal and written post-operative instructions were given to each patient and adequate antibiotic coverage with analgesics (Paracetamol tablets - 500mg) were prescribed. For research purposes, it should be noted that strong analgesics (i.e. both oral and injectable non-steroidal antiinflammatory pain killers such as voltaren$75 \mathrm{mg}$ were to be used only in cases of severe unbearable post-operative pain).

7. The patient was scheduled to be seen on the first (after 12 hours), second, third and $7^{\text {th }}$ post-operative day for data collection.

8. Criteria to be assessed in both groups were clinical and included pain, swelling and trismus and as follows:

Pain intensity was assessed based on a 4-point verbal descriptive scale (no pain, mild, moderate and severe pain ) on each of the scheduled visits. The days on which analgesics required were also recorded.

The level of discomfort was rated as follows ${ }^{(9)}$ :

0 - no pain.

1- Mild pain: recognizable but not discomforting pain that required no analgesics.

2- Moderate pain: discomforting but bearable pain (analgesics if used were effective in relieving pain)

3- Sever pain: difficult to bear (analgesics were effective in relieving pain).

$>\quad$ The amount of swelling is a very crude measure for inflammation. Swelling was rated as follows ${ }^{(10)}$ :

$0=$ None (no inflammation or swelling)

$1=$ Mild (intraoral swelling confined to the surgical field)

$2=$ Moderate (extraoral swelling in the surgical zone)

$3=$ Intense (extraoral swelling spreading beyond the surgical zone).

Degree of trismus: Pre-operative measurement of maximum mouth opening was recoded for each patient using a ruler with a mm scale. Readings were recorded for each patient on each scheduled visit. The incisal edges of the upper and lower central incisors were the upper and lower limits for this measurement ${ }^{(11)}$.

In regard to statistical analysis, data were loaded on computer using SPSS version 14.0. Descriptive statistics (frequency, percentage, mean and standard deviation) was used to assess the level of pain, swelling and trismus at the first day, second , third and first week recall visits. Analytical statistics used included Mann-Whitney $\mathrm{U}$ test for assessment of the difference between maxilla and mandible regarding pain and swelling, Friedman test to assess the difference among different recall visits for maxilla and mandible regarding pain and swelling. Student's $\mathrm{t}-$ test was used for 
assessment of difference between maxilla and mandible regarding trismus, and one way analysis of variance (ANOVA) for assessment of difference among different recall visits for maxilla and mandible regarding trismus. Difference at (or less than) 0.05 was considered significant.

\section{RESULTS}

The allocation of sample according to age and sex was shown in Table (1).

Table (1): Allocation of sample according to sex

\begin{tabular}{ll}
\hline Sex & Number \\
\hline Male & 32 \\
Female & 8 \\
\hline
\end{tabular}

The duration of surgical procedures for upper first molar teeth from incision to suture ranged from 20 to 35 minutes with an average duration of 28.4 minutes. The duration of surgical procedures for lower first molar teeth from incision to suture ranged from 30 to 40 minutes with an average duration of 36.3 minutes.

For the first criterion assessed, pain, the results showed the following:

In the mandible, and in the first day, mild pain was recorded in $30 \%$ (6) of subjects, moderate pain in 55\%(11) of subjects and severe pain in $15 \%$ (3) subjects. In the maxilla, and in the first day, mild pain was recorded in $60 \%$ (12) of subjects, moderate pain in 35\%(7) of subjects and severe pain in $5 \%$ (1) subject. On the second day, and in the mandible, mild pain was recorded in 50\% (10) of subjects, moderate pain in 45\%(9) of subjects and severe pain in 5\%(1) of subjects.. In the maxilla, mild pain was recorded in $95 \%$ (19) of subjects, moderate pain in 5\%(1) of subjects with no severe pain noticed. On the third day, and in the mandible, mild pain was recorded in 95\% (19) of subjects, moderate pain in 5\%(1) of subjects with no severe pain noticed. In the maxilla, absence of pain was recorded in $35 \%$ (7) of subjects and with mild pain in $65 \%$ (13) of subjects. On the first week recall visit, and in the mandible, absence of pain was recorded in 90\%(18) of subjects but with mild pain in 18\%(2) of subjects. In the maxilla, absence of pain was recorded in all subjects (100\%). A significant difference was observed between re- call visits in regard to pain level for mandibular procedures and maxillary procedures. In regard to pain level assessment between mandibular and maxillary procedures, a significant difference was observed with pain levels higher in mandibular procedures for the second and third day when compared to maxillary procedures. It should be noted that strong analgesics were not taken by any patient (other than paracetamol tab. $500 \mathrm{mg}$ ) in cases where there was severe pain perceived. The results were shown in Tables (2) and (3). Concerning, swelling, the results showed the following: In the mandible, and in the first day, mild swelling was recorded in $85 \%$ (17) of subjects, moderate swelling in $15 \%$ (3) of subjects. In the maxilla, and in the first day, mild swelling was recorded in $75 \%$ (15) of subjects, moderate swelling in $25 \%$ (5) of subjects. On the second day, and in the mandible, moderate swelling was recorded in $55 \%$ (11) of subjects, severe swelling in $45 \%(9)$ of subjects. In the maxilla, mild swelling was recorded in $65 \%$ (13) of subjects, moderate swelling in $35 \%$ (7) of subjects. On the third day, and in the mandible, moderate swelling was recorded in $65 \%$ (13) of subjects, severe swelling in $35 \%(7)$ of subjects. In the maxilla, mild swelling was recorded in 90\%(18) of subjects and moderate swelling in $10 \%$ (2) of subjects. On the first week recall visit, and in the mandible, absence of swelling was recorded in $90 \%$ (18) of subjects and no swelling in $10 \%(2)$ of subjects. 
Table (2): Assessment of pain levels in mandibular and maxillary procedures at the first, second , third and seventh day.

Frequency and percentage of pain levels

\begin{tabular}{|c|c|c|c|c|c|c|c|c|c|}
\hline \multirow[t]{2}{*}{ Jaw } & \multirow[t]{2}{*}{ No. } & \multicolumn{2}{|c|}{$1^{\text {st }}$ day } & \multicolumn{2}{|c|}{2 th day } & \multicolumn{2}{|c|}{$3^{\text {rd }}$ day } & \multicolumn{2}{|c|}{$7^{\text {th }}$ day } \\
\hline & & Nil & --- & Nil & --- & Nil & ---- & Nil & $18(90 \%)$ \\
\hline \multirow{3}{*}{ Mandible } & \multirow{3}{*}{20} & Mild & $6(30 \%)$ & Mild & $10(50 \%)$ & Mild & $19(95 \%)$ & Mild & $2(10 \%)$ \\
\hline & & Mod & $11(55 \%)$ & Mod & $9(45 \%)$ & Mod & $1(5 \%)$ & Mod & --- \\
\hline & & Sev & $3(15 \%)$ & $\mathrm{Sev}$ & $1(5 \%)$ & Sev & --- & $\mathrm{Sev}$ & ---- \\
\hline
\end{tabular}

Friedman test: $\chi^{2}=44.341, \mathrm{df}=3, p-$ value $=.000$

\begin{tabular}{|c|c|c|c|c|c|c|c|c|c|}
\hline & & \multicolumn{2}{|c|}{$1^{\text {st }}$ day } & \multicolumn{2}{|c|}{2 th day } & \multicolumn{2}{|c|}{$3^{\text {rd day }}$} & \multicolumn{2}{|c|}{$7^{\text {th }}$ day } \\
\hline \multirow{4}{*}{ Maxilla } & \multirow{4}{*}{20} & Nil & & Nil & & Nil & & Nil & $20(100 \%)$ \\
\hline & & Mild & $12(60 \%)$ & Mild & $19(95 \%)$ & Mild & $7(35 \%)$ & Mild & ----- \\
\hline & & Mod & $7(35 \%)$ & Mod & $1(5 \%)$ & Mod & $13(65 \%)$ & Mod & ----- \\
\hline & & $\mathrm{Sev}$ & $1(5 \%)$ & $\mathrm{Sev}$ & ----- & $\mathrm{Sev}$ & ---- & $\mathrm{Sev}$ & ----- \\
\hline
\end{tabular}

Friedman test: $\chi^{2}=48.660, \mathrm{df}=3, p-$ value $=.000$

Table (3): Mann-Whitney Test for assessment of pain levels between mandibular and maxillary procedures at the first, second, third and seventh day.

\begin{tabular}{|c|c|c|c|c|}
\hline & Pain $1^{\text {st }}$ day & Pain $2^{\text {nd }}$ day & Pain $3^{\text {rd }}$ day & Pain $7^{\text {th }}$ day \\
\hline Mann- Whitney U & 135.000 & 109.500 & 123.500 & 180.000 \\
\hline $\mathbf{Z}$ & -1.945 & -3.151 & -2.978 & -1.433 \\
\hline$p$-value & .052 & $.002 *$ & $.003 *$ & .152 \\
\hline
\end{tabular}

* Significant difference existed at $p \leq 0.05$.

In the maxilla, absence of swelling was recorded in all subjects (100\%). A significant difference was observed between recall visits in regard to swelling of soft tissue for mandibular and maxillary procedures. In regard to grade of swelling assessment between mandibular and maxillary procedures, a significant difference was observed with swelling of soft tissue higher in mandibular procedures on the second and third day when compared to maxillary procedures as shown in Tables (4) and (5).

The result of trismus were as follows: in mandibular molar procedures and on the first day, the mean decrease in mouth opening was $-7.70 \mathrm{~mm}$, on the second day $3.50 \mathrm{~mm}$, on the third day $-0.80 \mathrm{~mm}$ and on the first week recall visit trismus was absent. In maxillary molar procedures, and on the first day, the mean decrease in mouth opening was $-.55 \mathrm{~mm}$, on the second day $-65 \mathrm{~mm}$, on the third day $-0.60 \mathrm{~mm}$ and on the first week recall visit trismus was absent. A significant difference was observed for limitation of mouth opening in mandibular procedures between recall visits specifically on the first and second day but was not observed in maxillary procedures. When comparing between upper and lower surgical procedures, a significant difference was observed to trismus specially on the second and third postoperative day and which was more pronounced in mandibular procedures. Detailed results are as shown in Tables (6-11) 
Table (4): Assessment of swelling in mandibular and maxillary procedures at the first, second, third and seventh day.

\begin{tabular}{|c|c|c|c|c|c|c|c|c|c|}
\hline \multirow{3}{*}{ Jaw } & \multirow{3}{*}{ No. } & \multicolumn{8}{|c|}{ Frequency and percentage of swelling levels } \\
\hline & & \multicolumn{2}{|c|}{$1^{\text {st }}$ day } & \multicolumn{2}{|c|}{$2^{\text {nd }}$ day } & \multicolumn{2}{|c|}{$3^{\text {rd }}$ day } & \multicolumn{2}{|c|}{$7^{\text {th }}$ day } \\
\hline & & Nil & ----- & Nil & ----- & Nil & ----- & Nil & $18(90 \%)$ \\
\hline \multirow{3}{*}{ Mandible } & \multirow{3}{*}{$\mathbf{2 0}$} & Mild & $17(85 \%)$ & Mild & ----- & Mild & ----- & Mild & $2(10 \%)$ \\
\hline & & Mod & $3(15 \%)$ & Mod & $11(55 \%)$ & Mod & $13(65 \%)$ & Mod & ---- \\
\hline & & $\mathrm{Sev}$ & ----- & $\mathrm{Sev}$ & $9(45 \%)$ & Sev & $7(35 \%)$ & Sev & ------ \\
\hline \multicolumn{10}{|c|}{ Friedman test: $\chi 2=56.723, \mathrm{df}=3, p-$ value $=.000$} \\
\hline & & \multicolumn{2}{|c|}{$\mathbf{1}^{\text {st }}$ day } & \multicolumn{2}{|c|}{$2^{\text {nd }}$ day } & \multicolumn{2}{|c|}{$3^{\text {rd day }}$} & \multicolumn{2}{|c|}{$7^{\text {th }}$ day } \\
\hline \multirow{4}{*}{ Maxilla } & \multirow{4}{*}{20} & Nil & ------ & Nil & ----- & Nil & ----- & Nil & $20(100 \%)$ \\
\hline & & Mild & $15(75 \%)$ & Mild & $13(65 \%)$ & Mild & $18(90 \%)$ & Mild & ------ \\
\hline & & Mod & $5(25 \%)$ & Mod & $7(35 \%)$ & Mod & $2(10 \%)$ & Mod & ------ \\
\hline & & $\mathrm{Sev}$ & ----- & $\mathrm{Sev}$ & ----- & $\mathrm{Sev}$ & ------ & $\mathrm{Sev}$ & ------ \\
\hline
\end{tabular}

Friedman test: $\chi 2=51.188, \mathrm{df}=3, p-$ value $=.000$

Table (5): Mann-Whitney Test for assessment of swelling levels between mandibular and maxillary procedures at the first, second, third and seventh day.

\begin{tabular}{|c|c|c|c|c|}
\hline & Sweling1 ${ }^{\text {st }}$ day & Swelling $2^{\text {nd }}$ day & Swelling $3^{\text {rd }}$ day & Swelling $7^{\text {th }}$ day \\
\hline Mann- Whitney U & 180.000 & 38.500 & 13.000 & 180.000 \\
\hline $\mathbf{Z}$ & -.781 & -4.701 & -5.482 & -1.433 \\
\hline$p$-value & .435 & $.000^{*}$ & $.000^{*}$ & .152 \\
\hline
\end{tabular}

* Significant difference existed at $p<0.05$.

Table (6): Descriptive Statistics for degree of trismus at recall visits for both mandibular and maxillary procedures.

\begin{tabular}{|c|c|c|c|c|c|c|}
\hline Site & No & Day & $\operatorname{Min}(\mathbf{m m})$ & $\operatorname{Max}(\mathbf{m m})$ & Mean & Std. Deviation \\
\hline \multirow{4}{*}{ Mandible } & \multirow{4}{*}{20} & $1 \mathrm{st}$ & -11 & -2 & -7.70 & 2.155 \\
\hline & & $2^{\text {nd }}$ & -8 & -1 & -3.50 & 1.850 \\
\hline & & $3^{\text {rd }}$ & -4 & 0 & -.80 & 1.105 \\
\hline & & $7^{\text {th }}$ & 0 & 0 & .00 & .000 \\
\hline \multirow{4}{*}{ Maxilla } & \multirow{4}{*}{20} & $1 \mathrm{st}$ & -2 & 0 & -.55 & .759 \\
\hline & & $2^{\text {nd }}$ & -3 & 0 & -.65 & .933 \\
\hline & & $3^{\text {rd }}$ & -3 & 0 & -.60 & .940 \\
\hline & & $7^{\text {th }}$ & -1 & 0 & .00 & .308 \\
\hline
\end{tabular}


Table (7): Student's $t$-test values for trismus levels at different recall visits between mandibular and maxillary procedures.

\begin{tabular}{cccc}
\hline Day & \multicolumn{3}{c}{ t-test } \\
& $\mathbf{t}$ & $\mathbf{d f}$ & $\boldsymbol{p}$-value \\
\hline First day & -13.998 & 38 & $.000^{*}$ \\
Second day & -6.152 & 38 & $.000^{*}$ \\
Third day & -.616 & 38 & .541 \\
Seventh day & 1.453 & 38 & .154 \\
\hline
\end{tabular}

* Significant difference existed at $p \leq 0.05$.

Table (8): One way analysis of variance (ANOVA) for levels of trismus following mandibular procedures at recall visits.

\begin{tabular}{cccccc}
\hline & $\begin{array}{c}\text { Sum of } \\
\text { Squares }\end{array}$ & df & $\begin{array}{c}\text { Mean } \\
\text { Square }\end{array}$ & F-value & \multirow{2}{*}{$\boldsymbol{p}$-value } \\
\hline Between Groups & 723.600 & 3 & 241.200 & \multirow{2}{*}{103.918} & \multirow{2}{*}{$.000^{*}$} \\
Within Groups & 176.400 & 76 & 2.321 & & \\
\hline Total & 900.000 & 79 & & & \\
\cline { 1 - 4 }
\end{tabular}

* Significant difference existed at $p<0.05$.

Table (9): One way analysis of variance (ANOVA) for levels of trismus following maxillary procedures at recall visits.

\begin{tabular}{cccccc}
\hline & $\begin{array}{c}\text { Sum of } \\
\text { Squares }\end{array}$ & df & $\begin{array}{c}\text { Mean } \\
\text { Square }\end{array}$ & F-value & p-value \\
\hline Between Groups & 3.850 & 3 & 1.283 & 2.116 & \multirow{2}{*}{105} \\
Within Groups & 46.100 & 76 & .607 & & \\
\hline Total & 49.950 & 79 & & & \\
\hline
\end{tabular}

Table (10): Duncan's Multiple range test for trismus levels in mandibular procedures.

\begin{tabular}{cccc}
\hline Recall Visit & No. & Mean & $\begin{array}{c}\text { Duncan's } \\
\text { Grouping* }\end{array}$ \\
\hline $\mathbf{1}^{\text {ST }}$ day & 20 & -7.70 & $\mathrm{~A}$ \\
$\mathbf{2}^{\text {nd }}$ day & 20 & -3.50 & $\mathrm{~B}$ \\
$\mathbf{3}^{\text {rd }}$ day & 20 & -.80 & $\mathrm{C}$ \\
$\mathbf{7}^{\text {th }}$ day & 20 & .00 & $\mathrm{C}$ \\
\hline
\end{tabular}

* Means with different letters were statistically significant $(p<0.05)$.

Table (11): Duncan's Multiple range test for trismus levels in maxillary procedures.

\begin{tabular}{cccc}
\hline Recall Visit & No. & Mean & $\begin{array}{c}\text { Duncan's } \\
\text { Grouping }\end{array}$ \\
\hline $\mathbf{1}^{\text {ST }}$ day & 20 & -.65 & $\mathrm{~A}$ \\
$\mathbf{2}^{\text {nd }}$ day & 20 & -.60 & $\mathrm{~A}$ \\
$\mathbf{3}^{\text {rd }}$ day & 20 & -.55 & $\mathrm{~A}$ \\
$\mathbf{7}^{\text {th }}$ day & 20 & -.10 & $\mathrm{~A}$ \\
\hline
\end{tabular}

\section{DISCUSSION}

The difference between an acceptable and an excellent surgical out come often rests on how the surgeon handles the tissue. The use of proper incision and flap design techniques play a role; however tissue also must be handled carefully. Excessive pulling or crushing, extremes of temperature, desiccation, or use of nonphysiologic chemicals easily damage tis- 
sue. An axiomatic principle of surgery is that the longer the flap is retracted, the greater the complication following surgery. This seems a logical conclusion because the vascular flow is undoubtedly impeded during retraction and at some point in time, tissue hypoxia and acidosis will result in damage which may delay wound healing. ${ }^{(12)}$

This research compared the untoward post surgical sequel (pain, swelling, trismus) following upper and lower first molar apicectomy procedures. Regarding pain, statistical analysis showed a significant difference between upper and lower first molar at $1^{\text {st }}, 3^{\text {rd }}$ and $7^{\text {th }}$ day postoperatively in which the pain in the lower molar was superior to upper one (Tables $2,3)$. This may be due to the fact that the surgical entry through the osseous cortical plate to the mandibular molar is more often complicated by limited access, shallow vestibule, heavy cortical plate, presence of oblique ridge and root length, position and inclination. Although the apical extremities of molar roots are inclined buccally, roots are housed within thick cortical plate of bone. These anatomic entities increase difficulty and time required by the surgeon to complete his work. ${ }^{(13)}$ Since the degree of pain and edema is usually proportional to the time that the flap is retracted, ${ }^{(14)}$ this may explain why pain in mandibular region is greater than upper area, in addition; the pain that a patient may experience after a surgical procedure is highly variable and depends a greatest deal on patient's preoperative frame of mind and his / her pain threshold. ${ }^{(15)}$ This finding is also accepted by Kvist and Reit in which their patients experienced pain and $67 \%$ took analgesics after surgical endodontic treatment. ${ }^{(16)}$

Concerning swelling; the statistical comparison showed significant difference among the study groups. Surgical wounding trigger the release of mediators like kinins, histamin, serotonin, leukotrienes that influence on the microcirculature and altering vascular permeability resulting in outpouring of protein- rich fluid (exudates) into extra vascular tissue. Furthermore; the lymphatic obstruction by fibrin will aggravate edema which reach it's maximum 24 to 88 hours following surgery and begin to subside on $3^{\text {rd }}$ to $4^{\text {th }}$ day and resolved by the end of first week. Two variables help to determine the degree of post surgical edema: first the greater amount of tissue injury; the greater amount of edema, second the more loose connective tissue that is contained in injured region, the more edema is present. ${ }^{(17)}$

The difference in swelling (Tables 4,5) between upper and lower molar at $\left(1^{\text {st }}, 2^{\text {nd }}\right.$, $\left.3^{\text {rd }}, 7^{\text {th }}\right)$ days with edema was more significant in lower region can be interpreted from a histological point of view. In the upper region, the surface epithelium of palatal mucosa and attached gingiva are thick containing very dense collagen fibers and are tightly bound to the underlying periosteum and bone, so it exhibits little tendency toward edema; however, in the lower region, the floor of the mouth contains a large amount of loose connective tissue and can swell significantly. ${ }^{(18,19)}$ McCagie insisted that when some surgeons extend the incision in to the sulcus, a venous plexus may be encountered which may give rise to a brisk ooze resulting in more swelling. ${ }^{(17)}$

The result of trismus (Tables 6-11) revealed that this complication occurs in the majority of mandibular molar surgery. This may be due to inflammation involving the muscles of mastication or as a result of multiple injections of local anesthesia, especially if the injections have penetrated muscles. The muscle most likely to be involved is medial pterygoid muscle which may be inadvertently penetrated by local anesthetic needle during the inferior alveolar nerve block. ${ }^{(20)}$ In addition, with mandibular surgery the patients have to stay in an uncomfortable position for along time which causes strain on the masticatory muscles. ${ }^{(16)}$

\section{CONCLUSIONS}

On the basis of the results of the clinical trial, it appears that complications following apicectomy on lower first molar teeth are more pronounced when compared to the upper first molar region but only in the first ongoing days following surgery. However, such complications are bearable to the patient and can be overcome by medications and exercise and such complications should not hinder the oral surgeon from performing surgical en- 
dodontics on posterior teeth when indicated.

\section{REFERENCES}

1. Harty FJ. Endodontics in Clinical Practice. $2^{\text {nd }} E d$. John Wright and Sons Ltd, Stonebridge Press, Bristol .1982; Pp:1-6.

2. Craig RG. Restorative Dental Materials . $10^{\text {th }}$ Ed. C.V. Mosby Company, Saint Louis.1997;Pp1-15.

3. Hession RW. Long term evaluation of endodontic treatment. Int Endod J. $1981 ; 14: 179$.

4. Ray HA, Trope M. Periapical status of endodontically treated teeth in relation to the technical quality of the root filling and the coronal restoration. Int Endod J . 1995 ; 28: 12-18.

5. Sundqvist $\mathrm{G}$, Figdor $\mathrm{D}, \mathrm{Sj}^{\wedge}$ gren $\mathrm{U}$. Microbiologic analysis of teeth with failed endodontic treatment and the outcome of conservative retreatment. Oral Surg Oral Med Oral Pathol Oral Radiol Endod .1998; 85: 86-93.

6. Stock C, Walker R, Gulabivala K. Endodontics. $3^{\text {rd }}$ Ed. C.V. Mosby Company, London . 2004 ; P : 225.

7. Gutmann JL, Harrison JW. Surgical endodontics. $1^{\text {st }}$ Ed. Ishiyaku EuroAmerica, Inc.Publishers, U.S.A. 1999; Pp : 203-277.

8. Suleiman MS . A clinical study of the medical condition of patients requiring tooth extraction in Mosul City. AlRafidain Dent J. 2002; 2 : 414-422.

9. Yoldas O, Topuz A, Isci AS: Postoperative pain after endodontic retreatment: Single-versus two-visit treatment. Oral Surg Oral Med Oral Pathol 2004; 98: 483.

10. Tsesis I, Fuss Z, Lin S: Analysis of postoperative symptoms following surgical endodontic treatment. Quintessence Int . 2003; 34: 756

11. Celic R, Jerimilov V, Knezovic Zlataric D. Relationship of slightly limited mandibular movements to temporomandibular disorders. Braz Dent J. 2004; 15(2): 151-154.

12. Peterson LJ. Contemporary oral and maxillofacial surgery. $4^{\text {th }}$ edition. Mosby co.2003: p44.

13. Gutman JL. Harrison JW. Surgical endodontics. Periradicular surgery. Chapter six-surgical access. $1^{\text {st }}$ Ed. Ishiyaku EuroAmerica, Inc. USA. 1999; Pp 153-182.

14. Wein FS. Endodontic therapy. periapical surgery. $5^{\text {th }}$ edition. Mosby co. 1996. pag. 569.

15. Peterson LJ. Contemporary oral and maxillofacial surgery. $4^{\text {th }}$ edition. Mosby co. 2003. pag. 216.

16. Igor T. Comparism of quality of life after surgical endodontic treatment using two techniques: A prospective study . Oral Surg Oral Med Oral Pathol Oral Radiol Endod. 2005 ; 99 : 367-71.

17. McCagie J. A Standard procedure for the removal of unerupted wisdom teeth. Dent Prac . 1957 ; 7: 150-154.

18. Peterson LJ. Contemporary oral and maxillofacial surgery. $4^{\text {th }}$ edition. Mosby co.2003. pag.

19. Bhaskar.SN.Orban's oral histology and embryology. $10^{\text {th }}$ edition. C.v. mosby co.1986.P.293.

20. Malamed SF. Handbook of local anesthesia. 5th edition. Mosby, Inc. 2004. pag. 291. 